\title{
Daily Emotional Labor, Negative Affect State, and Emotional Exhaustion: Cross-Level Moderators of Affective Commitment
}

\author{
Hyewon Kong ${ }^{1}$ and Joo-Eon Jeon ${ }^{2, *}$ \\ 1 College of Liberal Arts and Interdisciplinary Studies, Kyonggi University, Suwon 16227, Korea; \\ hwkong@kgu.ac.kr \\ 2 Department of Business Administration, Anyang University, Anyang 14028, Korea \\ * Correspondence: eric@anyang.ac.kr
}

Received: 9 May 2018; Accepted: 8 June 2018; Published: 12 June 2018

\begin{abstract}
Employees' emotional-labor strategies, experienced affects, and emotional exhaustion in the workplace may vary over time within individuals, even within the same day. However, previous studies on these relationships have not highlighted their dynamic properties of these relationships. In addition, although the effects of surface and deep acting on emotional exhaustion have been investigated in emotional-labor research, empirical studies on these relationships still report mixed results. Thus, we suggest that moderators may affect the relationship between emotional labor and emotional exhaustion. Also, this study examines the relationship between emotional labor and emotional exhaustion within individuals by repeated measurements, and verifies the mediating effect of a negative affect state. Finally, our study confirms the moderating effects that affective commitment has on the relationship between emotional labor and emotional exhaustion. Data was collected from tellers who had a high degree of interaction with clients at banks based in South Korea. A total of 56 tellers participated in the survey and responded for five working days. A total of 616 data entries were collected from the 56 respondents. We used a hierarchical linear model (HLM) to examine our hypothesis. The results showed that surface-acting emotional labor increases emotional exhaustion; furthermore, the relationship between surface acting emotional labor and emotional exhaustion is mediated by a negative affect state within individuals. In addition, this study verified that affective commitment buffers the negative effects that surface acting emotional labor has on emotional exhaustion. These results suggest that emotional labor is a dynamic process within individuals, and that emotional exhaustion caused by emotional labor differs among individuals, and is dependent upon factors such as the individual's level of affective commitment.
\end{abstract}

Keywords: emotional labor; emotional exhaustion; affect; affective commitment; multi-level; experience sampling; hierarchical linear model (HLM)

\section{Introduction}

In service firms, service quality plays a key role in organizational performance [1,2]. Service providers are often directly linked to the quality of service experienced by customers [2]. As a result, a company's employees are perceived as the most important assets of the corporation; many companies enhance their competitiveness through the acquisition and maintenance of excellent talent. As such, effective employee management can also have a significant impact on the sustainability of service companies [3,4]. This study is important from a human resources perspective, particularly in the area of employee retention, because it investigates the factors that make it difficult for service organization employees to perform their jobs. 
Service providers are expected to perform emotional labor in accordance with the organization's emotional display rules while interacting with customers [2]. Emotional labor is defined as work performed according to the emotions required by an organization, regardless of the emotions that employees actually feel. In general, emotional labor has been known to increase not only emotional exhaustion, but also turnover rates [3,4]. In addition, as the frequency of interaction with customers is increased, emotional exhaustion also increases [3,5]. As a result, emotional exhaustion caused by emotional labor can have a negative impact on employees' career management by increasing the turnover rates of employees [6].

Previous studies have reported that emotional labor has a negative impact on emotional exhaustion. However, the effect of emotional labor on emotional exhaustion depends on the type of emotional labor. For example, it has been reported that while surface acting increases emotional exhaustion [1,7-9], deep acting is not associated with emotional exhaustion or reduced emotional exhaustion. In fact, researchers suggest that deep acting has been found to have a negative effect on emotional exhaustion $[4,10,11]$.

The conflicting results regarding the relationship between emotional labor and emotional exhaustion can be explained by one of two reasons [5,7]. First, the results indicate that there are various moderators in the relationship between emotional labor and emotional exhaustion. Second, most relevant previous studies have been cross-sectional, using a single measurement that relies on individual retrospectives

Emotional labor can also be different within individuals. Service providers encounter various customers during the workday and experience a variety of emotional events related to the job characteristics in the workplace. This means that an individual's psychological state can be constructive, depending on the customers they face. A previous study pointed out that emotional labor and emotions are so dynamic that emotional labor must be verified according to individuals' timeframes. Nevertheless, most previous studies have been cross-sectional, and emotional dynamics have not been measured accurately within individuals $[1,4]$. Therefore, in order to accurately understand the consequences of emotional labor, it is necessary to study the subtleties of emotional labor that exist within individuals.

In addition, affective commitment can be an important factor. Because affective commitment connects organizational goals with the core values of individuals, it can serve as an emotional resource, in that it supports a positive attachment to the organization. To buffer the negative effect of emotional labor, it may be useful to explain how emotional labor, negative affect state, and emotional exhaustion are experienced differently within individuals.

The purpose of this study is to provide a theoretical and practical contribution to the sustainability of service organizations. First, we examine the dynamic relationship between emotional labor, affect state, and emotional exhaustion. Second, we verify the mediating effects that affectivity has on the relationship between emotional labor and emotional exhaustion within individuals. Finally, we investigate the cross-level moderating effect affective commitment has on the relationship between emotional labor and emotional exhaustion. The experience sampling method was used to determine whether or not emotional labor processes are different within in different individuals. By proposing an effective emotional labor strategy to reduce emotional exhaustion, this study will be useful for the sustainability of service organizations.

\section{Theoretical Background and Hypotheses}

\subsection{Emotional Labor}

Emotional labor is defined as the effort required to express emotions according to the display rules required by organizations, regardless of the real emotions felt by employees, while providing services [2]. Emotional labor is based on the emotional regulation theory, which provides useful implications for surface acting and deep acting [3]. 
Employees who must perform emotional labor can choose to engage in either surface acting or deep acting to regulate their emotions. Although there are similarities between the two, in that they both express emotions according to the display rule of an organization, there are differences regarding the point at which the emotional regulation is expected to occur [12].

Individuals can engage in response-focused or antecedent-focused emotional regulation [3]. Response-focused emotional regulation is consistent with the process of surface acting. For example, an employee may express a fake smile in order to be courteous towards dissatisfied customers. In the process, the employee shows a tendency towards giving an emotional response, but controls the emotional response by "directly influencing the physiological, experiential, or behavioral responding" $[3,13]$. Surface acting is possible only when the employee suppresses or hides his or her internal emotions according to the situational context, and engages with the appropriate emotional expression as mandated by the organization $[13,14]$. In surface acting, emotional dissonance commonly occurs between the real emotion of the employee and the emotion required to be expressed during the provision of services; thus, the employee performs continued self-monitoring and behavior modification. Because the responses in surface acting are flexible according to the service situations, surface acting is considered a response-focused regulation.

In contrast, antecedent-focused emotional regulation corresponds with deep acting. In deep acting, an employee controls his or her emotions prior to providing a service. An employee engages in antecedent-focused emotional regulation in order to modify their perception of the situation, or to change emotions in order to meet display rule of organization $[3,13]$. To meet the emotional requirements of the organization, an employee either performs attention deployment, which modifies the focus of his or her own viewpoint, or they make a cognitive change by readjusting their emotions prior to providing the service. Thus, in terms of emotional labor, deep acting is considered a psychological process of antecedent-focused regulations.

\subsection{Emotional Labor (Surface Acting vs. Deep Acting) and Emotional Exhaustion}

Emotional exhaustion refers to the depletion of resources and fatigue caused by chronic or excessive job demands [15-17]. Emotional labor often contributes to emotional exhaustion. A considerable number of employees exhaust their emotional resources when they must express certain emotions, regardless of their real emotions, in adhering to rules of emotional expression $[2,18]$.

The effects of emotional labor on emotional exhaustion are based on the conservation of resources theory (COR) and emotional dissonance. According to COR, resource losses and gains are central concepts, and the former is associated with the job performance of employees [12]. Employees expend their skills, time, and energy in the process of job performance, and they employ their mental resources according to organizational demands. When employees use personal resources to handle organizational demands, they do not experience resource reduction or stress. Conversely, when a job is perceived as overwhelming and exceeding the limit that an individual can handle, he or she experiences a decrease in the level of available emotional resources. In applying COR to emotional labor, employees who must adhere to the expression rules of the organization experience excessive job stress while performing emotional labor, which exhausts their individual emotional resources [12,18].

The amount of exhausted resources varies according to the type of emotional labor. Thus, it is likely that the emotional exhaustion of employees who opt for surface acting would be greater than the emotional exhaustion resulting from deep acting. As discussed, employees who choose surface acting continue to monitor themselves, and occasionally perform behavior modification to avoid breaking the rules. On the other hand, employees who choose deep acting align themselves with the appropriate emotion in advance. Accordingly, less effort is required for those using deep acting to control themselves, and no significant behavior modification is necessary. In short, those who perform surface acting experience emotional exhaustion caused by resource loss more easily compared with those who engage in deep acting $[7,9,19]$. 
A previous study that empirically investigated individual differences in deep acting and emotional exhaustion suggested that deep acting and emotional exhaustion are not associated with each other [4]. It is proposed that individual differences in both emotional labor and emotional exhaustion are associated with each other only when surface acting is performed, as expressed in the following hypothesis:

Hypothesis 1 (H1). Within individuals, surface acting is positively related to emotional exhaustion.

\subsection{Mediating Effects of Negative Affect}

Emotional exhaustion is related to a person's affective state. Affects, feelings, and moods are often used interchangeably to describe emotional states. However, affect is a term that covers a broader category, encompassing emotions and moods. In emotional labor research, affect variables are divided into dispositional affectivity and state affectivity. First, a dispositional affectivity is perceived as an individual personality trait that underlies a person's dispositional tendencies.

Dispositional affect is mainly classified into positive and negative affectivity. Positive affectivity describes the predisposition of individuals to react positively to environmental stimuli, and negative affectivity represents the predisposition to respond negatively to environmental stimuli [20]. State affect is a mood or emotion that is temporarily experienced by a certain event $[4,21,22]$. State affects are related to psychological factors. Positive affectivity, for example, relates to pleasurable events, and is associated with satisfaction and active social activities. Negative affectivity is associated with unpleasant events, and is primarily related to adverse effects on stress and health [21,22].

The affects experienced by employees in the workplace vary depending on the type of emotional labor. This study expected that the emotional exhaustion caused by surface acting would be mediated by the negative affect. In surface acting, employees experience emotional dissonance, in which real emotions and expressed emotions conflict with each other. Consequently, employees experience self-deception, which is considered a type of negative affect [5].

Furthermore, the more an employee suppresses the negative affect by surface acting, the stronger the negative affect becomes [1]. For example, surface acting can make an individual's negative feelings worse as a result of emotional labor, because individuals express their emotion without changing their primary affect states. These results demonstrate an ironic effect; studies have shown that the more an individual attempts to suppress negative emotions, the more the negative feelings can be intensified, by causing the individual to think more about the situation that caused the negative emotions $[1,23]$. According to Clark and Watson [21,22], negative affects are associated with stress and health problems. Also, Judge et al. [4] argued that negative affects caused by surface acting can have a significant influence on the emotional exhaustion of employees.

This study proposes that surface acting influences the emotional exhaustion caused by emotional labor. Furthermore, it was predicted that employees would experience negative affects as a direct result of surface acting, thereby exacerbating their emotional exhaustion. Based on this discussion, the following hypothesis was proposed:

Hypothesis 2 (H2). Within individuals, surface acting will increase state negative affect.

Hypothesis 3 (H3). Within individuals, the relationship between surface acting and emotional exhaustion is mediated by state negative affect.

\subsection{Moderating Effects of Affective Commitment}

Affective commitment is considered an essential resource, in that people with affective commitment are motivated and willing to devote efforts and loyalty to the organization to which 
they belong. Affective commitment is defined as employees' affection for, identification with, and commitment to their organization. It serves as a motivating resource that helps employees control their behavior and emotions while interacting with customers [24]. Employees affectively committed to their organization accept and internalize the organizational goals and values. They not only have a strong motivation to achieve the goals, but also to demonstrate a solid sense of belonging [25]. When affective commitment is strong, employees identify themselves with the organization; such commitment has a positive influence on individual and organizational performance [26,27].

Employees performing emotional labor can experience emotional exhaustion, but the impacts may vary according to the resource capacity of the individuals, including their affective commitment to the organization [12,14]. Employees can control their emotions beforehand according to the organization's rules of expression, and provide services while hiding their real emotions when necessary [13]. Regardless of how they choose to do so, employees are forced to change their emotions as the organization requires [3]. In this context, when employees have a strong affective commitment to the organization, the negative effects of emotional exhaustion caused by surface acting may be less than when their affective commitment is weak.

Employees with a high level of affective commitment have an abundance of internal resources available; hence, they have the capability to relieve short-term emotional exhaustion resulting from surface acting. Additionally, as they identify with their organization-which is beyond a sense of belonging-employees maintain a strong internal motivation to achieve organizational goals in situations where they are required to control their emotions. Thus, their emotional exhaustion is milder. The following hypothesis was formulated:

Hypothesis 4 (H4). Affective commitment moderates the relationship between surface acting and emotional exhaustion within the individual; the within-individual relationship between daily surface acting and emotional exhaustion is weaker for individuals with a higher affective commitment than for individuals with a lower affective commitment.

\section{Methods}

\subsection{Data Collection and Procedures}

For empirical testing, data was collected from tellers who had a high degree of interaction with clients at banks based in South Korea. A total of 56 tellers participated in the survey over five working days. Respondents were employees engaged in customer service: $75 \%$ of them were responsible for teller service, and $25 \%$ for loan service. Female tellers accounted for $64 \%$ of the respondents, and permanent employees accounted for $87.5 \%$. The average age was 31 years (ranging from 24 to 52 years), and the average work experience was 6 years. The questionnaire was conducted with the cooperation of the bank manager. Before we conducted the survey, we explained the research purpose to the participants. All surveys were conducted with the written consent of the participants. The experience sampling method was applied to an online survey used for data collection. An arbitrary ID number from 1 to 56 was given to each of the respondents who agreed to participate in the online survey, and they were required to respond using the same account throughout the week.

The questionnaire consisted of three versions. First, all workers responded to questions about demographic characteristics and affective commitment before participating in the survey. Then, all workers responded to questions regarding emotional labor, emotional state, and emotional exhaustion for five working days. Measurements were conducted twice daily. Since bankers are not permitted to use mobile phones at work, each individual's affect state was measured before starting work, while emotional labor, state affect, and emotional exhaustion were measured at the end of the work day. Thus, we used average scores of affect state before and after work to measure state affects during work.

A total of 616 data entries were collected from the 56 respondents. Response data from the morning and evening surveys accounted for 280 entries each; answers regarding individual demographical 
and personal characteristics accounted for 56 entries. Respondents who completed the experience sampling survey throughout the week were given an online gift certificate worth $\$ 25$.

\subsection{Measures}

The questionnaire items were developed in English. Because this study was conducted in South Korea, a translation-back translation process was used [28]. First, all the questionnaire items of the survey were translated into Korean, and were later translated back into English by two bilingual researchers, to cross-check the accuracy of the translations.

\subsubsection{Emotional Labor: Surface Acting and Deep Acting}

To measure emotional labor, we adopted the surface acting (four items) and deep acting (six items) measurement used by Brotheridge and Lee [29] and Grandey et al. [5], in conjunction with a 5-point Likert scales $(1=$ almost never, $5=$ very often). Examples of statements rated by participants include "Today I resisted expressing my true feelings" for surface acting, "Today I tried to actually experience the emotions that I must show" for deep acting, "Today I generally tried to look at the positive side of things to change how I feel" for deep acting (positive refocusing), and "Today I tried to see things from the other person's point of view" for deep acting (perspective-taking). (Cronbach's alpha for surface acting 0.918; Cronbach's alpha for deep acting 0.924)

\subsubsection{Emotional Exhaustion}

To measure emotional exhaustion, five items were measured using the Maslach and Jackson metric [17]. Responses were measured on a 5-point Likert scale ( $1=$ strongly disagree, $5=$ strongly agree) regarding the amount of emotional exhaustion employees felt during the day. An example item is: "Today I felt emotionally drained from my work". This measurement system has been used in several diary- and event-sampling studies $[12,30]$ to measure emotional exhaustion. (Cronbach's alpha 0.919).

\subsubsection{Workplace Negative Affect}

To measure the state negative emotions of individuals in the workplace, we used the five items from the PANAS Scale (Positive Affect and Negative Affect Schedule), developed by Watson, Clark, and Tellegen [21]. Negative moods (e.g., "anxious" and "upset") were also measured using a 5-point Likert scale ( $1=$ not at all, $5=$ very much). (To estimate the state of negative affect caused by surface acting, we used the average value of the state of negative affect before work and after work; Cronbach's alphas were 0.944 and 0.933 , respectively).

\subsubsection{Affective Commitment}

Affective commitment was measured using the five items developed by Allen and Meyer [31,32], along with a 5-point Likert scale ( $1=$ strongly disagree, $5=$ strongly agree). An example item is: "This organization has a great deal of personal meaning to me." (Cronbach's alpha 0.930).

\subsection{Analysis}

The data set consisted of hierarchical data with days nested within individuals. We used hierarchical linear modeling to examine the hypothesis, similar to the study of Scott and Barnes [1]. The hierarchical linear model is often called a multilevel model. To analyze HLM, SAS PROC MIXED, Mln, and MLwiN statistical programs were used. However, the most widely used program was HLM, proposed by Raudenbush and Bryk [33]. HLM is useful for analyzing multilevel, longitudinal data, or diary methods. The HLM is used for two purposes: the first is when we gauge a more accurate estimation of lower-level effects within higher-level units; the second is when we observe the change within individuals over time. 
The data of this research consisted of two levels. The lower level (level 1) included the five days of data that was collected based on employee responses towards emotional labor (surface acting, deep acting), state negative affect, and emotional exhaustion. The upper level (level 2) included demographic characteristics such as sex, age, career, and income as control variables (all categorical variables were converted into dummy variables). In addition, affective commitment was inputted at level 2 to test the cross-level moderating effect of affective commitment. Thus, it was possible to verify the difference between level 1 and level 2 .

To test the hypotheses, we regressed each consequence variable on the predictor variables; all predictors at level 1 were group-mean centered (individual mean) following the proposal of Hoffmann, Griffin, and Gavin [34]. Also, we added affective commitment as a level 2 predictor to test the cross-level moderating effect on the between-individual relationship; this variable was grand-mean centered.

\section{Results}

\subsection{Descriptive Statistical Analysis}

\subsubsection{Descriptive Statistics, Reliability, and Correlations}

The values of the means, standard deviations, reliability, and between- and within-individuals correlations among all the key variables are shown in Table 1. Cronbach's alpha coefficients are presented in parentheses. Above the diagonal line represents the between-person correlation of the 56 tellers, and that below represents the within-person correlation of the 280 daily surveys across 56 bankers. The average and standard deviations are the average and standard deviation values for the within-person data of the 56 tellers. Thus, surface acting was positively correlated with emotional exhaustion within individuals $(\mathrm{r}=0.586, p<0.01)$, whereas deep acting was not correlated with emotional exhaustion $(\mathrm{r}=-0.088, p<0.01)$.

Table 1. Descriptive statistics and correlations.

\begin{tabular}{|c|c|c|c|c|c|c|c|c|c|}
\hline Variables & Mean & SD & (1) & $(2)$ & (3) & (4) & (5) & (6) & (7) \\
\hline (1) Positive affect state, before work & 3.31 & 0.70 & & $-0.512 * *$ & -0.217 & $-0.400 * *$ & 0.201 & $-0.526^{* *}$ & $0.468^{* *}$ \\
\hline (2) Negative affect state, before work & 1.70 & 0.65 & $-0.515 * *$ & & $0.469 * *$ & 0.180 & -0.133 & $0.445^{* *}$ & -0.231 \\
\hline (3) Daily negative affect state & 1.35 & 0.43 & $-0.163^{* *}$ & $0.431 * *$ & & -0.164 & -0.173 & 0.135 & 0.210 \\
\hline (4) Daily surface acting & 2.96 & 0.97 & $-0.353 * *$ & $0.256^{* *}$ & 0.027 & & 0.057 & $0.359^{* *}$ & -0.221 \\
\hline (5) Daily deep acting & 3.33 & 0.69 & $0.210 * *$ & -0.064 & $-0.133 *$ & 0.113 & & $-0.321^{*}$ & 0.039 \\
\hline (6) Daily emotional exhaustion & 2.68 & 0.85 & -0.398 ** & $0.346^{* *}$ & $0.165^{* *}$ & $0.586^{* *}$ & -0.088 & & $-0.450^{* *}$ \\
\hline (7) Affective commitment & 3.61 & 0.80 & & & & & & & \\
\hline
\end{tabular}

Notes: ${ }^{*} p<0.05 ; * *<0.01$.

\subsubsection{Partitioning the Variance within and between Individuals}

We confirmed the results of the null models in HLM for the endogenous level-1 variables to determine whether there was a within-individual variance to account for. After estimating the null model for each variable, a within-individual variance was verified. The partitioning results demonstrated that a within-individual variance existed, showing surface acting (69\%), deep acting $(65 \%)$, workplace negative affect $(75 \%)$, and emotional exhaustion $(63 \%)$ in order (see Table 2). This implies that our hypothesis should be verified using HLM. 
Table 2. Parameter estimates and variance components of null model for level-1 endogenous variables.

\begin{tabular}{|c|c|c|c|c|}
\hline Variables & Intercept & $\begin{array}{l}\text { Within-Individual } \\
\text { Variance }(\sigma 2)\end{array}$ & $\begin{array}{l}\text { Between-Individual } \\
\text { Variance }(\tau 00)\end{array}$ & $\begin{array}{c}\text { Percentage of } \\
\text { within-Individual Variance }\end{array}$ \\
\hline Surface acting & $2.96^{*}$ & 0.89 & 0.40 * & $0.69 \%$ \\
\hline Deep acting & $3.36^{*}$ & 0.40 & $0.22 *$ & $0.65 \%$ \\
\hline State negative affect & $2.15 *$ & 0.65 & 0.23 & $0.74 \%$ \\
\hline Emotional exhaustion & $2.68 *$ & 0.64 & $0.38^{*}$ & $0.63 \%$ \\
\hline
\end{tabular}

Notes: Within-individual $\mathrm{n}=280$, between-individual $\mathrm{n}=56$. The percentage of variance within individuals was computed using $\sigma 2 /(\sigma 2+\tau 00) .{ }^{*} p<0.001$.

\subsection{Hypothesis Testing}

\subsubsection{Main Effects of the Emotional Labor}

Hypothesis 1 predicted that surface acting would cause emotional exhaustion (Table 3 ). The results showed that surface acting has a significant effect on emotional exhaustion $(b=0.27, p<0.01)$. Thus, Hypothesis 1 was supported. In addition, although not hypothesized in this study, we verified the relationship between deep acting and emotional exhaustion. Consequently, the relationship between deep acting and emotional exhaustion was not significant $(b=-0.03, p=$ n.s. $)$.

Table 3. HLM results of predicting emotional exhaustion.

\begin{tabular}{|c|c|c|c|c|c|c|c|c|c|}
\hline \multirow[b]{2}{*}{ Variables } & \multicolumn{3}{|c|}{ Emotional Exhaustion } & \multicolumn{3}{|c|}{ State Negative Affect } & \multicolumn{3}{|c|}{ Emotional Exhaustion } \\
\hline & $\beta$ & s.e. & $t$ & $\beta$ & s.e. & $t$ & $\beta$ & s.e. & $t$ \\
\hline Intercept & 2.69 & 0.47 & $5.74^{* *}$ & 2.09 & 0.44 & $4.74^{* *}$ & 2.69 & 0.47 & $5.74^{* *}$ \\
\hline Gender & -0.05 & 0.21 & -0.24 & -0.29 & 0.22 & -1.30 & -0.05 & 0.21 & -0.24 \\
\hline Age & -0.08 & 0.05 & -1.54 & -0.01 & 0.06 & -0.17 & -0.08 & 0.05 & -1.54 \\
\hline Tenure & -0.47 & 0.25 & -1.84 & 0.64 & 0.20 & $3.23^{* *}$ & -0.47 & 0.25 & -1.84 \\
\hline Work experience & 0.08 & 0.06 & 1.36 & 0.01 & 0.07 & 0.19 & 0.08 & 0.06 & 1.36 \\
\hline Job & 0.23 & 0.22 & 1.04 & -0.22 & 0.22 & -1.00 & 0.23 & 0.22 & 1.04 \\
\hline $\begin{array}{l}\text { Positive affect state } \\
\text { before work }\end{array}$ & -0.11 & 0.07 & -1.50 & 0.19 & 0.06 & $3.30 *$ & -0.17 & 0.07 & $-2.44 *$ \\
\hline $\begin{array}{c}\text { Negative affect state } \\
\text { before work }\end{array}$ & 0.11 & 0.08 & 1.31 & 0.39 & 0.09 & $4.17^{* *}$ & -0.01 & 0.09 & -0.11 \\
\hline Daily surface acting & 0.27 & 0.09 & $3.13^{* *}$ & 0.11 & 0.05 & $2.26^{*}$ & 0.24 & 0.08 & $2.94^{*}$ \\
\hline Daily deep acting & -0.03 & 0.11 & -0.26 & -0.19 & 0.06 & $-2.89 *$ & 0.03 & 0.10 & 0.27 \\
\hline Daily negative affect & & & & & & & 0.30 & 0.12 & $2.32 * *$ \\
\hline
\end{tabular}

Hypothesis 2 predicted that, within individuals, surface acting would increase a state of negative affect. As shown Table 3, surface acting has a significant effect on the state of negative affect $(b=0.11$, $p<0.05)$. Therefore, Hypothesis 2 was supported.

\subsubsection{Mediating Effect of Negative Affect}

Hypothesis 3 suggested that state negative affect has a mediating effect on the relationship between surface acting and emotional exhaustion within an individual. As presented in Table 3, the state of negative affect $(b=0.30, p<0.05)$ was significantly associated with emotional exhaustion. Also, the coefficients for surface acting reduced slightly $(b=0.27, p<0.05 \rightarrow b=0.24, p<0.05)$ when the state of negative affect was controlled. Specifically, to establish whether the relationship was mediated, we tested the significance of the indirect effects of surface acting on emotional exhaustion through the state of negative affect. In a previous study, Krull and MacKinnon [35] suggested the use of the first-order Taylor series expansion to gauge the standard error of the indirect effect [36] when the 
sample size of level 2 is 50 . Thus, considering that the level-2 sample size of this study was 56 , we followed their suggestion. As a result, the indirect effects of surface acting on emotional exhaustion through the state of negative affect was marginally significant $(\mathrm{z}=1.65, p<0.10)$. Thus, Hypotheses 3 was rejected.

\subsubsection{Cross-Level Moderating Effect of Affective Commitment}

In this study, Hypothesis 4 suggested affective commitment has a cross-level moderating effect on the relationship between surface acting and emotional exhaustion. The results revealed the moderating effects of affective commitment $(b=-0.20, p<0.05)$ (Table 4$)$. To determine the moderating effect of affective commitment, a simple slope change of emotional exhaustion was plotted on \pm 1 SD [37]. As shown in Figure 1, no significant relationship between surface acting and emotional exhaustion existed when the affective commitment was high. However, the positive relationship between the two variables increased significantly when affective commitment was low. Employees who were emotionally committed to the organization showed less emotional exhaustion resulting from surface acting. This indicates that those with low affective commitment experience greater emotional exhaustion as the degree of surface acting increases. Based on these results, Hypothesis 4 was supported (Table 4).

Table 4. Results for cross-level moderating effects.

\begin{tabular}{ccccc}
\hline & Variables & $\boldsymbol{\beta}$ & s.e. & $\mathbf{t}$ \\
\hline & Intercept & 2.52 & 0.41 & $6.11^{* *}$ \\
& Gender & 0.02 & 0.19 & 0.10 \\
Control variables & Age & -0.06 & 0.05 & -1.16 \\
& Tenure & -0.17 & 0.28 & -0.63 \\
& Work experience & 0.07 & 0.05 & 1.28 \\
& Job & 0.17 & 0.20 & 0.89 \\
& Positive affect state before work & -0.14 & 0.07 & $-1.96^{*}$ \\
& Negative affect state before work & 0.11 & 0.07 & 1.48 \\
\hline level 2 & Affective commitment & -0.40 & 0.14 & $-2.84^{* *}$ \\
\hline \multirow{2}{*}{ Cross: level 1 } & Daily surface acting & 0.25 & 0.08 & $3.29^{* *}$ \\
level 2 & Daily surface acting $\times$ affective commitment & -0.20 & 0.09 & $-2.29^{* *}$ \\
& Daily deep acting & -0.09 & 0.11 & -0.80 \\
& Daily deep acting $\times$ affective commitment & -0.04 & 0.13 & -0.30 \\
\hline
\end{tabular}

Notes: Level-1 variables $=$ group mean centering, level- 2 variables $=$ grand mean centering, dummy variables $=$ no centering. Gender: $0=$ female, $1=$ male; job: $0=$ teller service, $1=$ loan service; tenure: $0=$ nonpermanent, $1=$ permanent; work experience $=$ years. ${ }^{*} p<0.05 ;{ }^{* *} p<0.01$.

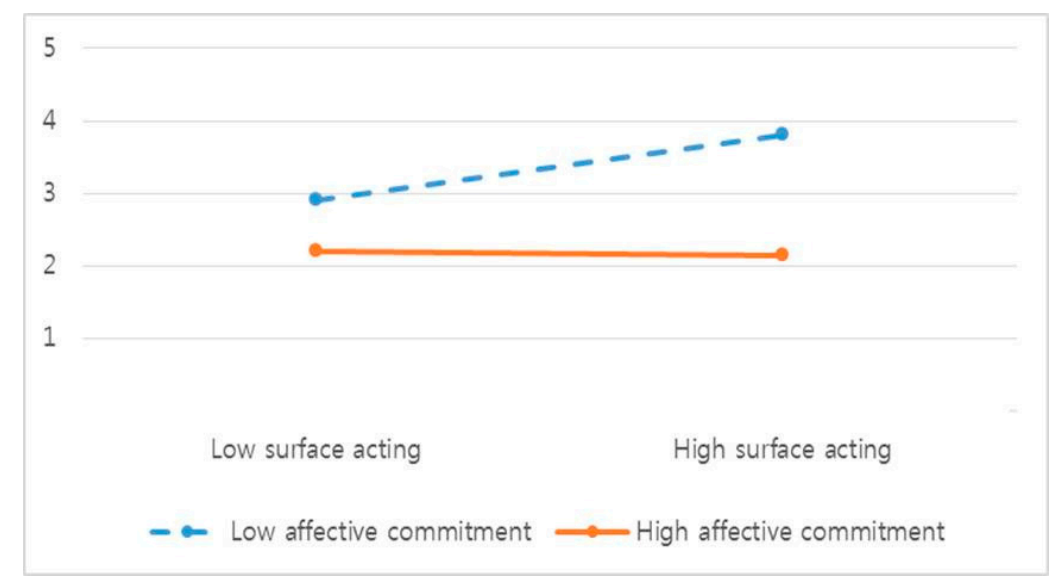

Figure 1. Moderating effects of affective commitment on the relationship between surface acting and emotional exhaustion. 


\section{Discussion}

\subsection{Results}

This study focused on the assumption that there is variance in the relationship between emotional labor and emotional exhaustion within individuals. Results of the study are as follows.

First, surface acting induced emotional exhaustion but deep acting did not. The employees that used surface acting continually exhausted their available resources because they repeatedly suppressed their natural emotions to express the required emotions. Conversely, employees who chose deep acting aligned their real emotions with the required emotions prior to providing services. Thus, it was predicted that emotional labor would not lead to emotional exhaustion. The study results showed that employees who performed emotional labor by engaging in surface acting experienced emotional exhaustion, whereas those who engaged in deep acting did not experience exhaustion.

Second, surface acting was found to increase states negative affective and emotional exhaustion. These results are consistent with the results of Scott and Barnes [1] and Judge et al. [4]. The results also support the argument of Wegner [23], that workers" efforts to suppress their negative feelings lead to an ironic effect that enhances the negative feelings of the individual $[1,23]$. Third, the results show that the cross-level moderating effect of affective commitment significantly impacts the relationship between surface acting and emotional exhaustion. Specifically, the positive relationship between surface acting and emotional exhaustion was stronger with a lower level of affective commitment. That is, a person with a high affective commitment may experience less emotional exhaustion from surface acting than a person with a low affective commitment. Based on these results, people with a high level of affective commitment experience less emotional exhaustion because they have a surplus of psychological resources similar to affective commitment, though they also lose emotional resources by surface acting.

Finally, taken together, these results reinforce the notion that "emotional labor is a dynamic process" [1] by showing that the types and consequences of emotional labor vary within and between individuals. Also, affective commitment can play a moderating role in a relationship where surface acting worsens emotional exhaustion. Thus, the effects of emotional labor can be different depending on the level of employees' affective commitment. These findings support Bono and Vey's [38] argument that the study of emotional labor should be conducted in both between- and within-individual perspective.

\subsection{Implications}

The implications of the results are as follows. First, the findings are significant because measurements were performed repeatedly to clarify the relationship between emotional labor and emotional exhaustion, as well as exploring how negative affect contributes to this relationship. The study concluded that employees experience a negative affect state when they perform surface acting.

Second, although it was not hypothesized in this study, it was confirmed that deep acting reduced negative emotions. For service organizations, employees who provide services directly to customers have a significant impact on organizational performance including service quality. Therefore, it should be possible to reduce the negative emotions experienced in the workplace by education and training employees to perform deep acting rather than surface acting when performing emotional labor.

Third, this study explored the role of personal resources, such as affective commitment, in order to find ways to relieve emotional exhaustion resulting from surface acting. Thus, this study provides further confirmation of COR theory. Employees' emotional exhaustion caused by surface acting was seen to be lessened by increased affective commitment. This suggests that affective commitment can play a meaningful role in supplementing or regaining the emotional resources that employees lose while performing their jobs. This implies that managers should have a plan to encourage the organizational commitment of their employees. For example, autonomy, or simply giving employees more control of their jobs, helps inspire employees to feel committed to their organization [10,24]. 
Finally, this implies that people with low level of affective commitment may be vulnerable to surface acting. For example, new employees who have low affective commitment may experience emotional exhaustion when they surface act. This can ultimately have a negative impact on organizational performance. Therefore, managers should understand the negative effects of surface acting and educate employees on how to use desirable emotional labor strategies in an effort to promote the organization's sustainability and improve the quality of the services provided.

\subsection{Limitations and Future Study Suggestions}

Based on the results, the following suggestions are offered for future study. First, there are methodological limitations to measuring emotional labor, negative affectivity, and emotional exhaustion. In this study, we hypothesized that emotional labor induces a state negative affect, and that this may cause emotional exhaustion. However, since these variables were measured at the end of the workday, these relationships may demonstrate reverse causation. Therefore, in future studies, it will be necessary to collect experience sampling data through a rigorous measurement design in order to clarify the causality between these relationships.

Second, this study focused on emotional exhaustion as a possible outcome variable of emotional labor. However, employees may feel a sense of achievement or efficacy while interacting with satisfied customers $[7,10]$. Therefore, in future research, practical implications can be provided by verifying various causal relationships using factors such as achievement and efficacy.

Finally, previous studies investigating individual differences have consistently reported that surface acting increases emotional exhaustion; however, their findings have often differed in terms of deep acting. Currently, there is a lack of research investigating within-individual differences, compared with those focused on between-person differences. Therefore, it is inappropriate to generalize the findings of previous research. Future studies should investigate a broader variety of service organizations and more diverse contextual environments, in order to produce a theoretical foundation that can elucidate the discordant results concerning emotional labor and emotional exhaustion.

Author Contributions: H.K. and J.-E.J. conceived the framework of this paper; H.K. developed the research model, collected the data, analyzed the data and wrote the paper; J.-E.J. developed the research objectives, designed the coordination mechanism.

Conflicts of Interest: The authors declare no conflict of interest.

\section{References}

1. Scott, B.A.; Barnes, C.M. A multilevel field investigation of emotional labor, affect, work withdrawal, and gender. Acad. Manag. J. 2011, 54, 116-136. [CrossRef]

2. Hochschild, A.R. The Managed Heart; University of California Press: Berkeley, CA, USA, 1983; ISBN 9780520272941.

3. Grandey, A.A. Emotional regulation in the workplace: A new way to conceptualize emotional labor. J. Occup. Health Psychol. 2000, 5, 95-110. [CrossRef] [PubMed]

4. Judge, T.A.; Woolf, E.F.; Hurst, C. Is emotional labor more difficult for some than for others? A multilevel, experience-sampling study. Pers. Psychol. 2009, 62, 57-88. [CrossRef]

5. Grandey, A.A.; Dickter, D.N.; Sin, H.P. The customer is not always right: Customer aggression and emotion regulation of service employees. J. Organ. Behav. 2004, 25, 397-418. [CrossRef]

6. Kraemer, T.; Gouthier, M.H.J. How organizational pride and emotional exhaustion explain turnover intentions in call centers: A multi-group analysis with gender and organizational tenure. J. Serv. Manag. 2014, 25, 125-148. [CrossRef]

7. Brotheridge, C.M.; Grandey, A.A. Emotional labor and burnout: Comparing two perspectives of "people work". J. Vocat. Behav. 2002, 60, 17-39. [CrossRef]

8. Brotheridge, C.M.; Lee, R.T. Testing a conservation of resources model of the dynamics of emotional labor. J. Occup. Health Psychol. 2002, 7, 57-67. [CrossRef] [PubMed] 
9. Grandey, A.A. When "the show must go on": Surface acting and deep acting as determinants of emotional exhaustion and peer-rated service delivery. Acad. Manag. J. 2003, 46, 86-96.

10. Ashforth, B.E.; Humphrey, R.H. Emotional labor in service roles: The influence of identity. Acad. Manag. Rev. 1993, 18, 88-115. [CrossRef]

11. Liu, Y.; Prati, L.M.; Perrewe, P.L.; Ferris, G.R. The relationship between emotional resources and emotional labor: An exploratory study. J. Appl. Soc. Psychol. 2008, 38, 2410-2439. [CrossRef]

12. Totterdell, P.; Holman, D. Emotion regulation in customer service roles: Testing a model of emotional labor. J. Occup. Health Psychol. 2003, 8, 55-73. [CrossRef] [PubMed]

13. Nguyen, H.; Groth, M.; Johnson, A. When the going gets tough, the tough keep working: Impact of emotional labor on absenteeism. J. Manag. 2016, 42, 615-643. [CrossRef]

14. Scott, B.A.; Barnes, C.M.; Wagner, D.T. Chameleonic or consistent? A multilevel investigation of emotional labor variability and self-monitoring. Acad. Manag. J. 2012, 55, 905-926. [CrossRef]

15. Goldberg, L.S.; Grandey, A.A. Display rules versus display autonomy: Emotion regulation, emotional exhaustion, and task performance in a call center simulation. J. Occup. Health Psychol. 2007, 12, 301-318. [CrossRef] [PubMed]

16. Grandey, A.; Foo, S.C.; Groth, M.; Goodwin, R.E. Free to be you and me: A climate of authenticity alleviates burnout from emotional labor. J. Occup. Health Psychol. 2012, 17, 1-14. [CrossRef] [PubMed]

17. Maslach, C.; Jackson, S.E. The measurement of experienced burnout. J. Organ. Behav. 1981, 2, 99-113. [CrossRef]

18. Sliter, M.; Jex, S.; Wolford, K.; McInnerney, J. How rude! Emotional labor as a mediator between customer incivility and employee outcomes. J. Occup. Health Psychol. 2010, 15, 468-481. [CrossRef] [PubMed]

19. Diefendorff, J.M.; Gosserand, R.H. Understanding the emotional labor process: A control theory perspective. J. Organ. Behav. 2003, 24, 945-959. [CrossRef]

20. Cropanzano, R.; James, K.; Konovsky, M.A. Dispositional affectivity as a predictor of work attitudes and job performance. J. Organ. Behav. 1993, 14, 595-606. [CrossRef]

21. Watson, D.; Clark, L.A.; Tellegen, A. Development and validation of brief measures of positive and negative affect: The panas scales. J. Pers. Soc. Psychol. 1988, 54, 1063-1070. [CrossRef] [PubMed]

22. Watson-Clark, R.A.; Banquerigo, M.L.; Shelly, K.; Hawthorne, M.F.; Brahn, E. Model studies directed toward the application of boron neutron capture therapy to rheumatoid arthritis: Boron delivery by liposomes in rat collagen-induced arthritis. Proc. Nat. Acad. Sci. USA 1998, 95, 2531-2534. [CrossRef] [PubMed]

23. Wegner, D.M. Ironic processes of mental control. Psychol. Rev. 1994, 101, 34-52. [CrossRef] [PubMed]

24. Wang, M.; Liao, H.; Zhan, Y.; Shi, J. Daily customer mistreatment and employee sabotage against customers: Examining emotion and resource perspectives. Acad. Manag. J. 2011, 54, 312-334. [CrossRef]

25. Meyer, J.P.; Allen, N.J.; Allen, N.J. Commitment in the Workplace; Sage Publications: Thousand Oaks, CA, USA, 1997.

26. Eisenberger, R.; Armeli, S.; Rexwinkel, B.; Lynch, P.D.; Rhoades, L. Reciprocation of perceived organizational support. J. Appl. Psychol. 2001, 86, 42-51. [CrossRef] [PubMed]

27. Lee, J.; Peccei, R. Perceived organizational support and affective commitment: The mediating role of organization-based self-esteem in the context of job insecurity. J. Organ. Behav. 2007, 28, 661-685. [CrossRef]

28. Brislin, R.W.; Triandis, H.C. Handbook of Cross-Cultural-Psychology: Social Psychology; Allyn and Bacon: Boston, MA, USA, 1980.

29. Brotheridge, C.M.; Lee, R.T. Development and validation of the emotional labour scale. J. Occup. Organ. Psychol. 2003, 76, 365-379. [CrossRef]

30. Teuchmann, K.; Totterdell, P.; Parker, S.K. Rushed, unhappy, and drained: An experience sampling study of relations between time pressure, perceived control, mood, and emotional exhaustion in a group of accountants. J. Occup. Health Psychol. 1999, 4, 37-54. [CrossRef] [PubMed]

31. Allen, N.J.; Meyer, J.P. Construct validation in organizational behavior research: The case of organizational commitment. In Problems and Solutions in Human Assessment; Springer: New York, NY, USA, 2000; pp. 285-314.

32. Allen, N.J.; Meyer, J.P. Affective, continuance, and normative commitment to the organization: An examination of construct validity. J. Vocat. Behav. 1996, 49, 252-276. [CrossRef] [PubMed]

33. Raudenbush, S.W.; Bryk, A.S. Hierarchical Linear Models: Applications and Data Analysis Methods; Sage: Thousand Oaks, CA, USA, 2002; Volume 1. 
34. Hofmann, D.A.; Griffin, M.A.; Gavin, M.B. The application of hierarchical linear modeling to organizational research. In Multilevel Theory, Research, and Methods in Organizations: Foundations, Extensions, and New Directions; Jossey-Bass: San Francisco, CA, USA, 2000.

35. Krull, J.J.; MacKinnon, D.P. Multilevel mediation modeling in group-based intervention studies. Eval. Rev. 1999, 23, 418-444. [CrossRef] [PubMed]

36. Sobel, M.E. Asymptotic confidence intervals for indirect effects in structural equation models. In Sociological Methodology; Leinhardt, S., Ed.; American Sociological Association: Washington, DC, USA, 1982; pp. $290-312$.

37. Aiken, L.S.; West, S.G.; Reno, R.R. Multiple Regression: Testing and Interpreting Interactions; Sage: Thousand Oaks, CA, USA, 1991.

38. Bono, J.E.; Vey, M.A. Toward understanding emotional management at work: A quantitative review of emotional labor research. In Emotions in Organizational Behavior; Psychology Press: Thousand Oaks, CA, USA, 2005.

(c) 2018 by the authors. Licensee MDPI, Basel, Switzerland. This article is an open access article distributed under the terms and conditions of the Creative Commons Attribution (CC BY) license (http:/ / creativecommons.org/licenses/by/4.0/). 